\title{
Glückwünsche des Präsidenten des Bergmännischen Verbandes Österreichs zum 75. Geburtstag von Em.O.Univ.-Prof. Dipl.-Ing. Dr. mont. Hans Jörg Steiner
}

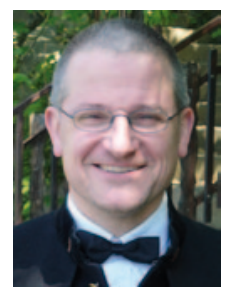

Fast vier Jahrzehnte hat Professor Steiner dem Institut für Aufbereitung und Veredlung an der Montanuniversität Leoben seinen unverkennbaren Stempel aufgedrückt und damit gleich mehrere Generationen von Bergingenieuren maßgeblich geprägt.

Besonderes Augenmerk richtete er neben der wissenschaftlichen Forschung auf die intensive Vermittlung des Fachwissens und auf die Förderung der Anwendungskompetenz seiner Mitarbeiter und Schüler. Er kannte dabei keine Scheu, Vorlesungen und Vorträge durch unkonventionelle Methoden aufzulockern. So ist mir noch deutlich erinnerlich, wie er Gesteinsproben direkt auf dem Schutzglas eines Projektors mit einem Hammer bearbeitete, um sofort in die Gesetzmäßigkeiten der Zerkleinerung und der Dispersität einzuführen.

Sein scharfer analytischer Verstand wurde dabei nicht wenigen Auszubildenden zu einer echten Herausforderung. Zudem hat er sich immer mit Nachdruck gegen eine
Verwaschung unserer Muttersprache gestellt. So bleibt wohl auch die Aufforderung: „Werter Kollege, könnten Sie den Satz bitte unter Weglassung lokaler Idiome wiederholen?", unvergessen.

Mit seinem unermüdlichen Wirken hat Professor Steiner einen wesentlichen Beitrag zum weltweit guten Ruf der montanistischen Ausbildung an unserer Alma Mater und zum breit gestreuten beruflichen Einsatzbild ihrer Absolventen beigetragen.

Mit Stolz, selbst einer seiner vielen Schüler gewesen zu sein, ist es mir eine besondere Freude und Ehre, dem Jubilar in meinem persönlichen und im Namen des Bergmännischen Verbandes Österreichs die besten Wünsche zu entbieten.

Möge er seinen tüchtigen Nachfolger und den Kreis der Leobener Aufbereiter weiterhin mit Rat und Tat unterstützen und uns alle an seinem großen Erfahrungsschatz teilhaben lassen.

Möge er seinen weiteren Lebensweg im Kreise seiner Familie und Freunde und im Kreise der Montanisten in Gesundheit, geistiger Frische und Harmonie verbringen.

Ad multos annos!

Dipl.-Ing. Martin Erich Lang // office@bvo.at Präsident des Bergmännischen Verbandes Österreichs 